\title{
Electrochemical CO Oxidation at Platinum on Carbon Studied through Analysis of Anomalous in Situ IR Spectra
}

Ian J. McPherson, ${ }^{\dagger}$ Philip A. Ash, ${ }^{\dagger}{ }^{\oplus}$ Lewys Jones, ${ }^{\S}$ (๑) Aakash Varambhia, ${ }^{\S}$ Robert M. J. Jacobs, ${ }^{\dagger}$ and Kylie A. Vincent*, ${ }^{+}$

${ }^{\dagger}$ Department of Chemistry, Inorganic Chemistry Laboratory, University of Oxford, South Parks Road, Oxford OX1 3QR, U.K.

${ }^{\S}$ Department of Materials, University of Oxford, 16 Parks Road, Oxford OX1 3PH, U.K.

${ }^{\ddagger}$ Department of Chemistry, Chemistry Research Laboratory, University of Oxford, 12 Mansfield Road, Oxford OX1 3TA, U.K.

\section{Supporting Information}

ABSTRACT: The oxidation of adsorbed $\mathrm{CO}$ is a key reaction in electrocatalysis. It has been studied extensively on both extended model surfaces and on nanoparticles; however, correlation between the two is far from simple. Molecular insight into the reaction is often provided using in situ IR spectroscopy; however, practical challenges mean in situ studies on nanoparticles have yet to provide the same level of detail as those on model surfaces. Here we use a new approach to in situ IR spectroscopy to study the mechanism of $\mathrm{CO}$ adlayer oxidation on a commercial carbon-supported Pt catalyst. We observe bipolar IR absorption bands but develop a simple model to enable fitting. Quantitative analysis of band behavior during the oxidation prepeak using the model agrees well with

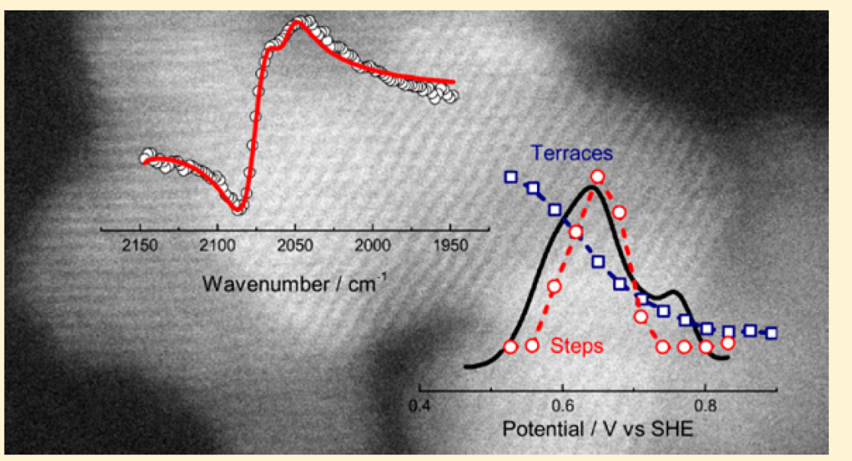
previous analysis based on conventional absorption bands. A second linear CO band is observed during the main oxidation region and is assigned to the distinct contribution of $\mathrm{CO}$ on step as opposed to terrace sites. Analysis of the step and terrace $\mathrm{CO}$ bands during oxidation shows that oxidation begins on the terraces of the nanoparticles before CO on steps is removed. Further correlation of this behavior with the current shows that step $\mathrm{CO}$ is only lost in the first of the two main oxidation peaks.

\section{INTRODUCTION}

Understanding the reactivity of $\mathrm{CO}$ at metal surfaces is of prime importance in fuel cell electrocatalysis. As a common contaminant in $\mathrm{H}_{2}$ feedstocks and an intermediate in the oxidation of many other candidate fuels (e.g., formic acid and methanol), ${ }^{1,2} \mathrm{CO}$ poisons catalysts by strongly adsorbing on the surface, blocking active sites. To maintain their activity, catalysts must therefore be capable of oxidizing $\mathrm{CO}$ alongside the fuel. An understanding of how and where $\mathrm{CO}$ oxidation takes place on the highly inhomogeneous surface of a typical nanoparticle (NP) catalyst is necessary for rational design of new CO-tolerant catalysts; ${ }^{3}$ however, such mechanistic details remain the subject of much debate. ${ }^{4-10}$

On $\mathrm{Pt}$, the most common fuel cell catalyst, the reaction is thought to occur via a Langmuir-Hinshelwood (LH) mechanism, as in the gas-phase reaction. ${ }^{11}$ In this scheme, adsorbed $\mathrm{CO}$ interacts with an adjacent adsorbed oxygencontaining species to produce $\mathrm{CO}_{2}{ }^{1,11}$ The oxygen species is most likely to be $\mathrm{OH}$, generated through partial oxidation of water, although other species have been suggested. ${ }^{12}$ Two principle mechanisms have been proposed to generate the adjacent $\mathrm{CO}$ and $\mathrm{OH}$ species necessary for reaction via a $\mathrm{LH}$ mechanism: the mean field (MF) model, in which diffusion of adsorbed $\mathrm{CO}$ is fast compared to the reaction rate, ensuring rapid mixing of the two species; $;^{4,13,14}$ and the nucleation and growth (NG) model, in which the species are immobile, form separate islands of $\mathrm{CO}$ and $\mathrm{OH}$ on the surface, and only react where their boundaries meet. ${ }^{15-18}$ In many cases, the MF model provides satisfactory fits to current transients measured during CO oxidation. ${ }^{13,19}$ In contrast, in situ IR spectroscopy shows evidence for dipole-dipole coupling between adsorbed $\mathrm{CO}$ molecules which is independent of global coverage, indicative of island formation. ${ }^{16,20}$ The NG model is also supported by recent work, which suggests that surface diffusion of $\mathrm{CO}$ is not as fast as previously thought. ${ }^{18,21,22}$

The situation is complicated further when considering that the MF and NG models represent two limiting cases. On real NP catalysts, relatively well-defined facets are connected via atoms with lower coordination numbers at edges and corners. ${ }^{23}$ These sites are generally more reactive toward adsorption (an effect rationalized by the upshift in the $d$-band center ${ }^{24}$ ) leading to mechanisms in which edges act as nucleation sites for $\mathrm{OH}$ formation. ${ }^{4,10,25}$ In addition, unlike semi-infinite macroscopic electrodes, NP catalysts have an intrinsic size distribution such

Received: March 7, 2017

Revised: July 21, 2017

Published: July 24, 2017 
that a range of size-dependent behavior can be exhibited by one catalyst sample. ${ }^{6,26,27}$ Furthermore, the NPs are commonly prepared on a conducting support, introducing NP loading as an additional parameter. For these reasons the mechanistic understanding of $\mathrm{CO}$ oxidation on NPs is far from complete.

Experimentally, CO oxidation on NPs is most commonly investigated using stripping voltammetry, in which a layer of $\mathrm{CO}$ is predosed onto the NP and then oxidized during a potential sweep in CO-free electrolyte. ${ }^{1,25,26}$ The position of the current peak(s) reveal the ease with which the catalyst can oxidize $\mathrm{CO}$ while the total charge passed enables estimation of the electrochemically active surface area. In most reports multiple peaks are observed, regardless of the electrode morphology (single--, ${ }^{28,29}$ poly- ${ }^{17,30}$ or nanocrystalline ${ }^{4,5,9}$ ). A small, broad peak is often seen at relatively low potentials $(0.5$ $\mathrm{V})$ while one or two sharper peaks are seen at higher potentials. No consensus exists for the origin of these peaks, with assignments being made to oxidation on: particles of different sizes, ${ }^{4,6,26}$ terrace and step sites, ${ }^{5,9}$ different crystal planes, ${ }^{7,31,5}$ and domains of different $\mathrm{CO} / \mathrm{H}_{2} \mathrm{O}$ composition. ${ }^{32}$ Furthermore, there are several aspects of $\mathrm{CO}$ oxidation on NPs which cannot easily be modeled on an extended surface. For example, the sharper CO stripping peaks shift to more positive potentials as the particle size decreases, despite the ratio of edge sites to terrace sites increasing. ${ }^{26,33}$ It has been suggested that this particle size effect may come from changes to the mobility of adsorbed $\mathrm{CO}$, which decreases with decreasing particle size., ${ }^{8,34}$ Other effects such as the particle loading on the support have also been found to have a dramatic effect on the shape of the voltammetry. $^{26}$ It is clear that further molecular-level information about $\mathrm{CO}$ stripping on NPs is required to resolve these contrasting theories.

In situ IR spectroscopy has provided a significant amount of information about $\mathrm{CO}$ adsorbed on extended surfaces, ${ }^{16,35-37}$ especially when well-defined single crystals have been studied in combination with scanning tunneling microscopy and surface X-ray scattering. ${ }^{28,38}$ Extension of IR techniques to NPs has been relatively successful; however, in general, the discussion and analysis of such data are still significantly less developed than that seen for the extended surfaces. ${ }^{39-48}$ In part, this is due to the various complications that arise when collecting IR spectra of species adsorbed on NPs. Aside from the inherent limitations of electrochemical IR reflection-absorption spectroscopy (resistance, bubbles, baseline changes due to changes in the electrolyte), the high refractive index of $\mathrm{Pt}$ coupled with the lower refractive index of an inert carbon supporting electrode can compromise the signal/noise $(\mathrm{S} / \mathrm{N})$ ratio and lead to deviations from conventional absorption band shapes. $^{48-51}$ To minimize these problems the nanoparticle film is often made as thin as possible, and more reflective, less inert, gold supporting electrodes are used. ${ }^{40,43-45,47,52,53}$ While these approaches are generally successful, the conditions still represent a compromise. In particular, thicker catalyst films will much better represent the state of the catalyst in membrane electrode assemblies. ${ }^{54}$

We therefore set out to investigate the mechanism of $\mathrm{CO}$ stripping on thick films of commercial Pt catalyst. We use an approach to in situ IR spectroelectrochemistry of supported catalysts which we reported recently. ${ }^{55}$ To fully interpret the data, which exhibit anomalous absorption behavior, we develop a model for the observed spectra. This enables us to fit and resolve overlapping bands and extract information on the $\mathrm{CO}$ adlayer as a function of potential and coverage. These data are then discussed in relation to the mechanism of $\mathrm{CO}$ oxidation on supported Pt nanoparticles.

\section{EXPERIMENTAL METHODS}

2.1. Reagents. Carbon-supported $\mathrm{Pt}(\mathrm{Pt} / \mathrm{C}, 60$ wt \% Pt, HiSPEC 9000) was obtained from Alfa Aesar. Sulfuric acid (Analytical reagent grade) was obtained from Fisher Scientific. Carbon monoxide gas (CP grade) was obtained from BOC. All solutions were prepared using ultrapure water $(18.2 \mathrm{M} \Omega \mathrm{cm}$, Milli-Q, Millipore). Reagents were used as received.

2.2. Microscopy. Particle morphology was characterized using high angle annular dark field scanning transmission electron microscopy (HAADF-STEM) on a JEOL JEM-3000F FEGTEM microscope operating at $300 \mathrm{kV}$ accelerating voltage. Samples were prepared by drop-casting a nanoparticle suspension (ultrasonically dispersed in analytic purity ethanol) onto a holey-carbon film $\mathrm{Cu}$ TEM grid.

2.3. Spectroelectrochemistry. All IR and electrochemical measurements were made in an in situ attenuated total reflectance IR (ATR-IR) spectroelectrochemical flow cell we reported recently for studying supported metal nanoparticles during electrocatalysis. ${ }^{55}$ In this approach, the catalyst is applied directly onto the surface of a Si internal reflection element (IRE) with the electrical connection being made from the top using porous carbon paper. This avoids introducing additional metal contacts which could interact with $\mathrm{CO}$ while maintaining the sensitivity and mass transport advantages of ATR sampling. With this approach, we are able to collect spectra with a very high $\mathrm{S} / \mathrm{N}$ ratio which allows fine potential resolution without resorting to very slow sweep rates. To prepare the catalyst layer, $\mathrm{Pt} / \mathrm{C}$ was added to ethanol (to $10 \mathrm{mg} \mathrm{mL}^{-1}$ ) and sonicated to form an evenly dispersed ink. Then $10 \mu \mathrm{L}$ of the ink was drop cast onto a Si IRE (sampling area ca. $5 \times 8 \mathrm{~mm}^{2}$ ) and allowed to dry in air. Catalyst films prepared in this way were found to be around $1 \mu \mathrm{m}$ thick. ${ }^{55}$ The IRE was sealed into a baseplate designed to fit a commercial ATR accessory (GladiATR, Pike Technologies) modified to provide five reflections at the catalyst layer/IRE interface. A homemade flow cell comprising a carbon flow field was used to press a sheet of carbon paper (Toray GDL) onto the film, and this allowed the potential of the catalyst layer to be controlled and solution to be flowed over the film. The cell contained a $\mathrm{Ag} / \mathrm{AgCl}$ reference electrode (BAS, Inc.) connected to the catalyst layer via a Luggin capillary and a $\mathrm{Pt}$ gauze counter electrode. Potentials are reported relative to the standard hydrogen electrode (SHE) using the conversion $E_{\mathrm{SHE}}=E_{\mathrm{Ag} / \mathrm{AgCl}}+0.209$ at $298 \mathrm{~K}^{56}$ The ATR accessory with flow cell was mounted in an FTS7000 FTIR spectrometer (Bio-Rad) fitted with a liquid $\mathrm{N}_{2}$ cooled $\mathrm{HgCdTe}$ detector. Electrochemistry was carried out in a threeelectrode configuration using a potentiostat ( $\mu$ Autolab II, Metrohm) which was fitted with an integrator. The integrated current determined by the potentiostat was used to ensure no oxidation current was lost in sampling the digital staircase potential sweep. A trigger signal from the spectrometer was used to start the electrochemical program enabling the two measurements to be synchronized. Further output signals to a dual peristaltic pump (Williams Manufacturing Co.) enabled the flow of solution to be controlled from within the electrochemical software (Nova 1.8, Metrohm). Spectra were recorded with a spectral resolution of $4 \mathrm{~cm}^{-1}$ and an initial time resolution of $0.202 \mathrm{~s}$. Spectra were subsequently coadded to reach the desired potential resolution and labeled corresponding to the mean potential. Spectra are reported in units of 
absorbance, calculated from the background spectrum without $\mathrm{CO}$ present (obtained either before $\mathrm{CO}$ adsorption or after $\mathrm{CO}$ oxidation, as specified) denoted $R_{0}$, and the sample spectrum with $\mathrm{CO}, R$, using eq 1 . For fitting the $y$ offset was adjusted to ensure each spectrum was centered around $y=0$. Band fitting was carried out in Matlab (R2014a).

$$
A=-\log _{10}\left(\frac{R}{R_{0}}\right)
$$

2.4. CO Stripping. Prior to CO stripping measurements the catalyst layer was cleaned by cycling between 0.0 and $1.2 \mathrm{~V}$ vs SHE 10 times. ${ }^{10,27,57} \mathrm{CO}$ adsorption was carried out by flowing CO-saturated electrolyte $\left(\mathrm{H}_{2} \mathrm{SO}_{4}, 0.5 \mathrm{M}\right)$ over the catalyst layer for $600 \mathrm{~s}$ at $4 \mathrm{~mL} \mathrm{~min}{ }^{-1}$ while it was held at $0.05 \mathrm{~V}$ vs SHE. Residual CO was then removed by flushing the cell (volume $\sim 40 \mu \mathrm{L}$ ) with $\mathrm{N}_{2}$-purged CO-free electrolyte at the same flow rate for a further $100 \mathrm{~s}$. The flow was then stopped, and $\mathrm{CO}$ oxidation was examined by stepping the potential to $0.0 \mathrm{~V}$ for 5 $\mathrm{s}$ and then cycling twice between 0.0 and $1.2 \mathrm{~V}$ at a rate of 10 $\mathrm{mV} \mathrm{s}^{-1}$.

\section{RESULTS AND DISCUSSION}

3.1. HAADF STEM Characterization. Characterization of the Pt particle size was carried out using HAADF-STEM, in which the image intensity is strongly dependent on the atomic number $(Z)$ and sample thickness. This means that the technique is highly suitable for studying catalyst nanoparticles supported on a low $Z$ support like carbon ( $Z$-contrast). ${ }^{23,58}$ Figure 1A shows an image of the carbon support coated in $\mathrm{Pt}$ particles. It can be seen that the metal component is composed of two main fractions: small, isolated spherical particles around $1 \mathrm{~nm}$ in diameter and agglomerates of larger particles with overall dimensions of 5-10 $\mathrm{nm}$. The $Z$-contrast nature of the image allows rapid estimation of the particle size distribution by automation. Automated sizing analysis was performed using an in-house Matlab script, based on 50 images with independent regions of interest and field of view (details can be found in Figure S1). A histogram of the individual (nonagglomerated) nanoparticles is shown in Figure 1B. A mean particle size of $1.81 \mathrm{~nm}$ is seen. Higher magnification images (Figure S1) reveal a high degree of crystallinity within the agglomerates, with the lattice fringes of adjoining particles appearing to be in register. Thus, while the constituent particles of the agglomerates are likely to present individual facets of around only $5 \mathrm{~nm}$ diameter, a continuous, ordered crystalline surface may extend over a much greater area.

3.2. CO Stripping Voltammetry. CO oxidation was examined using cyclic voltammetry (CV) following saturation of the catalyst surface with adsorbed CO. The potential was cycled twice between 0.0 and $1.2 \mathrm{~V}$ at a rate of $10 \mathrm{mV} \mathrm{s}^{-1}$ (Figure 2A). The first scan, shown in black, reveals the complete absence of current in the $\mathrm{H}$ desorption region (0.0$0.2 \mathrm{~V}$ ), confirming saturation of the surface with adsorbed CO. A broad current peak from 0.2 to $0.48 \mathrm{~V}$, labeled i, is observed before a couple of overlapping peaks at 0.64 and $0.76 \mathrm{~V}$, respectively (ii, iii). The second scan (red) reveals a pair of positive current peaks corresponding to $\mathrm{H}$ desorption, ${ }^{59,60}$ with relatively little current in the rest of the scan, except for a small peak at the same position as iii, showing that almost all CO was oxidatively removed in scan 1 . The shape of the $\mathrm{CV}$ is very similar to that reported previously on a similar catalyst, ${ }^{9}$ while a

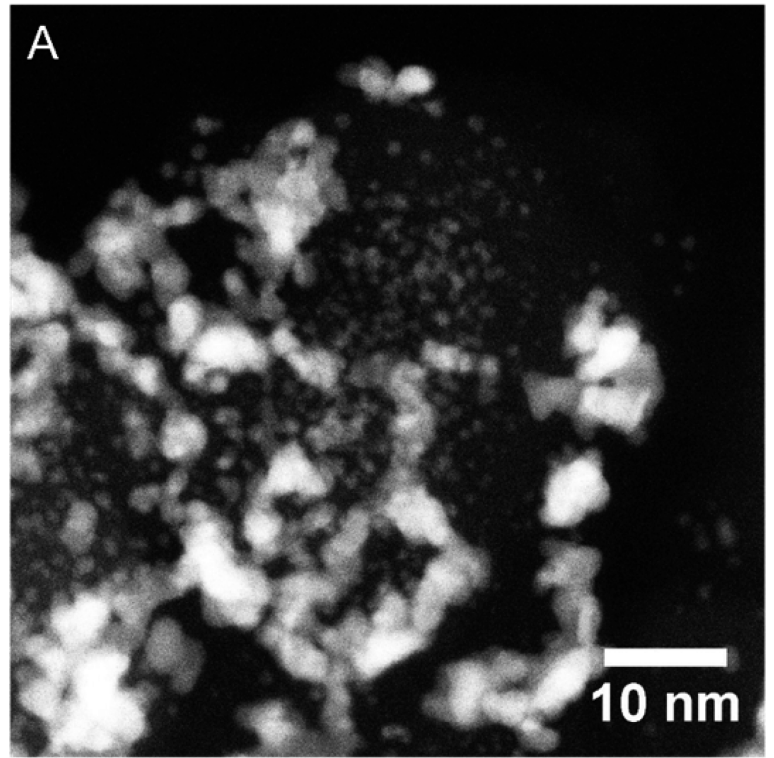

B

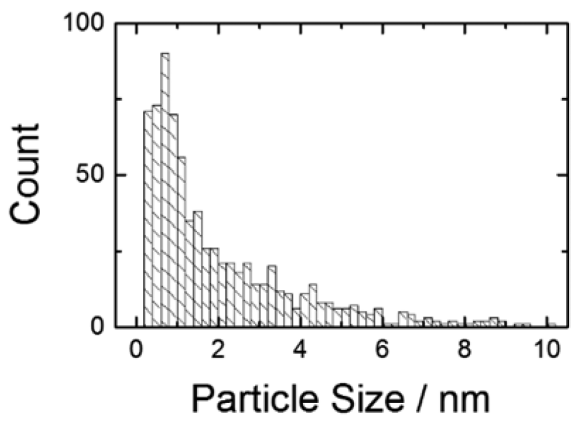

Figure 1. HAADF-STEM characterization of the Pt catalyst. (A) Overview image of catalyst showing both individual and agglomerated catalyst. Magnification $800000 \times$. (B) Histogram from automated particle size analysis of 875 individual catalyst particles obtained from 50 images. Mean particle size $1.81 \mathrm{~nm}$.

similar number of peaks have been reported on polycrystalline model electrodes. ${ }^{5,61}$

3.3. In Situ IR Spectroscopy. Spectra obtained at 0.05 and $1.2 \mathrm{~V}$ before and after oxidation of the $\mathrm{CO}$, respectively, are shown in Figure 2B. One dominant derivative-shaped band can be seen in the spectrum recorded at $0.05 \mathrm{~V}$, centered around $2050 \mathrm{~cm}^{-1}$. There is also a second much broader, less intense band centered around $1850 \mathrm{~cm}^{-1}$ (enlarged in Figure S2). IR bands in these two regions are generally thought to arise from $\mathrm{CO}$ adsorbed atop a single $\mathrm{Pt}$ site, known as linear $\mathrm{CO}$, and from $\mathrm{CO}$ adsorbed between two sites, known as bridging $\mathrm{CO}$, respectively. ${ }^{36}$ Note that with a couple of exceptions, ${ }^{44,45,62}$ only a single linear $\mathrm{CO}$ band is observed on NP catalysts at high coverage, despite the presence of multiple adsorption sites. $^{10,27,47}$ This is attributed to the strong dipole coupling between adsorbed $\mathrm{CO}$ molecules giving a single observed normal mode. Without additional information, such as splitting of the band, more specific assignment of the band is not possible.

The defining characteristic of the linear $\mathrm{CO}$ band is its striking bipolar shape, with both positive and negative components. This shape causes problems when it comes to quantitative analysis; simple numerical integration of the area 


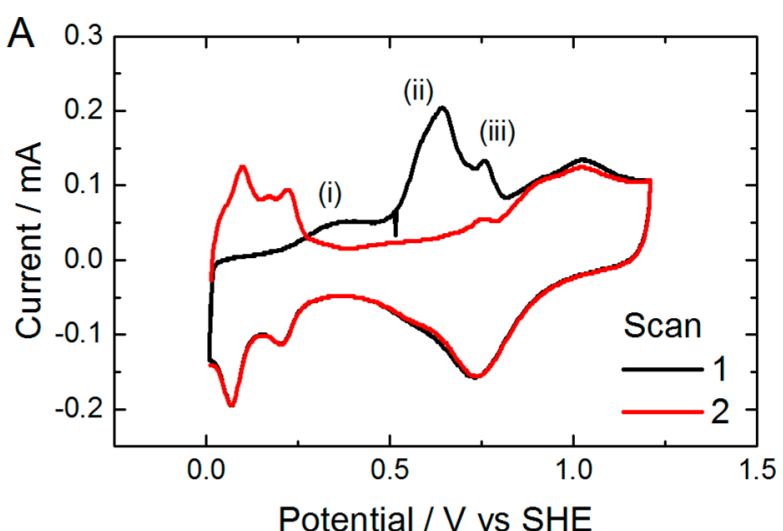

B

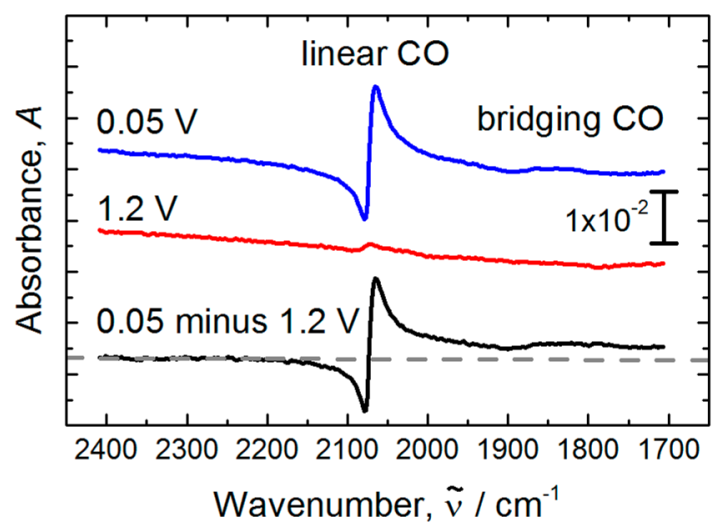

Figure 2. Spectroelectrochemical data obtained during $\mathrm{CO}$ monolayer oxidation at $\mathrm{Pt} / \mathrm{C}$. (A) Cyclic voltammograms in $0.5 \mathrm{M} \mathrm{H}_{2} \mathrm{SO}_{4}$ after $\mathrm{CO}$ adsorption at $0.05 \mathrm{~V}$ vs SHE. Scans 1 (black line) and 2 (red line) shown. Current peaks are seen at (i) $0.2-0.48$, (ii) $0.64 \mathrm{~V}$, (iii) $0.76 \mathrm{~V}$. Scan rate $10 \mathrm{mV} \mathrm{s}^{-1}$. (B) IR spectra of the $\mathrm{Pt} / \mathrm{C}$ at $0.05 \mathrm{~V}$ after CO adsorption (blue line) and after oxidation at $1.2 \mathrm{~V}$ (red line). Background: $0.05 \mathrm{~V}$ before introduction of $\mathrm{CO}$. The difference spectrum ( 0.05 minus $1.2 \mathrm{~V}$, black line) is also shown with a linear fit to the high wavenumber region (dashed gray line).

enclosed by the lobes may seem straightforward; however, closer inspection reveals that there is an apparent step change in baseline that occurs throughout the region; compare the baseline in the 0.05 minus $1.2 \mathrm{~V}$ difference spectrum on the high wavenumber side, extrapolated as the dashed gray line, with the baseline on the low wavenumber side. This effect makes choice of suitable limits for integration highly subjective. Furthermore, numerical integration cannot provide the individual integrated intensities of overlapping bands, nor does it provide obvious values for the band center or width. To extract this information the bands must therefore be fitted to a suitable model.

3.4. Band-Shape Model. The IR spectra of CO adsorbed on Pt nanoparticles has been simulated in a number of different ways for both reflection and transmission geometries. ${ }^{50,51,63-66}$ The approaches, which range in level of detail and complexity, all predict appropriate band shapes under certain conditions but to date do not appear to have been used to fit experimental data. We base our model on the simplified geometry shown in Figure 3, in which a single reflection is modeled for a catalyst layer which is thicker than the penetration depth, such that only 2 layers, the IRE and the catalyst layer, need to be considered. To generate a dielectric function to describe the complex, multiphase catalyst layer we adopt the approach of $\mathrm{Su}$ et al., who use the Bruggeman effective medium theory to combine

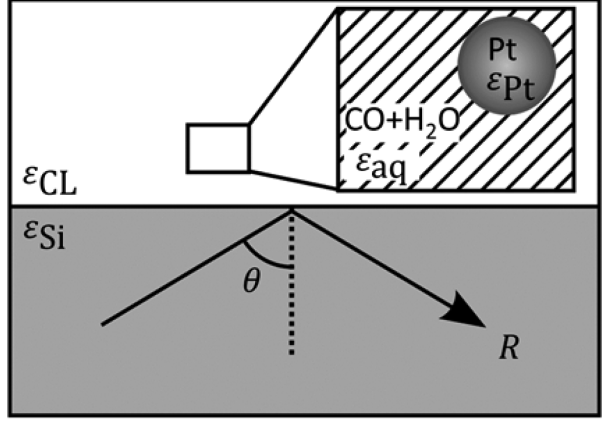

Figure 3. Geometry used to simulate absorption spectra. Pt nanoparticles (volume fraction $f$ ) immersed in a mixture of $\mathrm{CO}+$ $\mathrm{H}_{2} \mathrm{O}$ represent the catalyst layer, dielectric constant $\varepsilon_{\mathrm{CL}}$, which is deposited directly onto a Si IRE, dielectric constant $\varepsilon_{\mathrm{Si}}$. A reflectance $R$ is calculated from angle of incidence $\theta$.

the contributions of Pt nanoparticles (with volume fraction $f$ ) immersed in a so-called "mixed phase" consisting of water and CO. ${ }^{66}$

The metallic $\mathrm{Pt}$ is modeled with experimental values of the wavenumber-dependent dielectric constant $\varepsilon_{\mathrm{Pt}}{ }^{67}$ The dielectric constant of the "mixed phase", $\varepsilon_{\mathrm{aq}}$ is composed of real and imaginary parts, $\varepsilon_{\mathrm{i}}$ and $\varepsilon_{\mathrm{r}}$ (eq 2). A Lorentzian function is used to model the contribution of CO to $\varepsilon_{\mathrm{i}}$ (eq 3 ). The real part, $\varepsilon_{\mathrm{r}}$, is made up of a wavenumber-independent contribution from water, $n_{\mathrm{H} 2 \mathrm{O}}=1.316,{ }^{66}$ and the Kramers-Kronig transform of $\varepsilon_{\mathrm{j}}$ calculated using the double fast Fourier transform method. ${ }^{68,69}$ The dielectric functions $\varepsilon_{\mathrm{Pt}}$ and $\varepsilon_{\mathrm{aq}}$ were then combined into an effective dielectric constant for the catalyst layer, $\varepsilon_{\mathrm{CL}}$, using the Bruggeman effective medium theory (eq 5) with dimension $D$ $=3$ and volume fraction, $f$, allowed to vary between 0 and $1 .{ }^{66}$ The refractive indices of the catalyst layer and Si IRE, can be calculated using eq 6, which then enables the Fresnel reflection coefficient, $r$ (eq 7), and thus reflectance, $R$ (eq 8), to be found (angle of incidence $\theta=39^{\circ}, \varepsilon_{\mathrm{Si}}$ from ref 70 ). Unpolarized light was used in the experiments and so $R$ is taken as the sum of $s$ and $p$ components. To generate the background $R_{0}$ required for calculation of absorbance (eq 1), a background catalyst layer consisting solely of $n_{\mathrm{H} 2 \mathrm{O}}$ was used.

$$
\begin{aligned}
& \varepsilon_{\mathrm{aq}}=\varepsilon_{\mathrm{r}}-i \varepsilon_{\mathrm{i}} \\
& \varepsilon_{\mathrm{i}}(\tilde{\nu})=\frac{B \gamma \tilde{\nu}}{\left(\tilde{\nu}_{0}^{2}-\tilde{\nu}^{2}\right)^{2}+\gamma^{2} \tilde{\nu}^{2}} \\
& \varepsilon_{\mathrm{r}}(\tilde{\nu})=n_{\mathrm{H} 2 \mathrm{O}}^{2}+\frac{1}{\pi} \mathcal{P} \int_{-\infty}^{\infty} \frac{\varepsilon_{i}(\tilde{\nu}) \mathrm{d} \tilde{\nu}}{\left(\tilde{\nu}_{0}-\tilde{\nu}\right)} \\
& f \frac{\varepsilon_{\mathrm{Pt}}-\varepsilon_{\mathrm{CL}}}{\varepsilon_{\mathrm{Pt}}}+(D-1) \varepsilon_{\mathrm{CL}} \\
& \hat{n}=\sqrt{\varepsilon} \\
& r_{s}=\frac{\cos \theta-\sqrt{\left(\hat{n}_{\mathrm{CL}} / \hat{n}_{\mathrm{Si}}\right)^{2}-\sin ^{2} \theta}}{\cos \theta+\sqrt{\left(\hat{n}_{\mathrm{CL}} / \hat{n}_{\mathrm{Si}}\right)^{2}-\sin ^{2} \theta}}=0 \\
& r_{p}=\frac{\left(\hat{n}_{\mathrm{CL}} / \hat{n}_{\mathrm{Si}}\right)^{2} \cos \theta-\sqrt{\left(\hat{n}_{\mathrm{CL}} / \hat{n}_{\mathrm{Si}}\right)^{2}-\sin ^{2} \theta}}{\left(\hat{n}_{\mathrm{CL}} / \hat{n}_{\mathrm{Si}}\right)^{2} \cos \theta+\sqrt{\left(\hat{n}_{\mathrm{CL}} / \hat{n}_{\mathrm{Si}}\right)^{2}-\sin ^{2} \theta}}
\end{aligned}
$$




$$
R=\left|r_{s}+r_{p}\right|^{2}
$$

Figure $4 \mathrm{~A}$ shows the real and imaginary parts of the $\mathrm{CO}$ dielectric function plotted using some typical values used in this

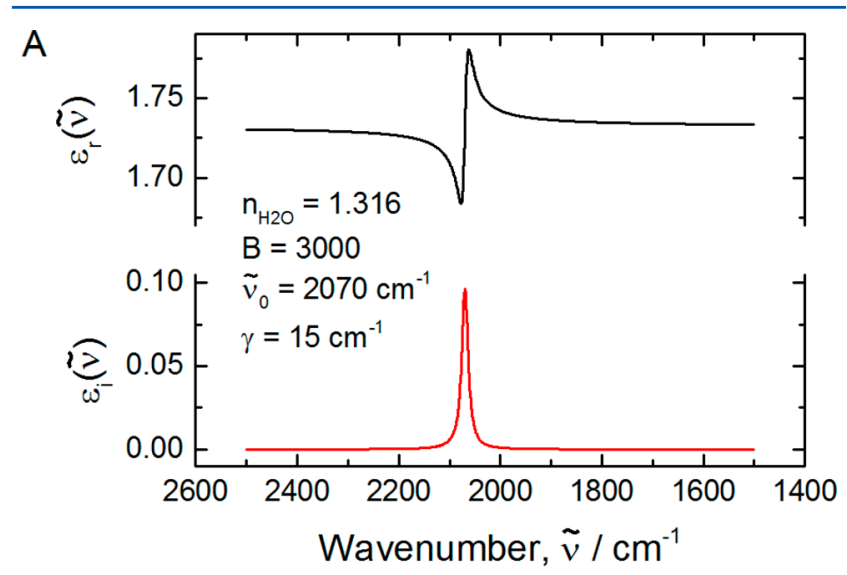

B

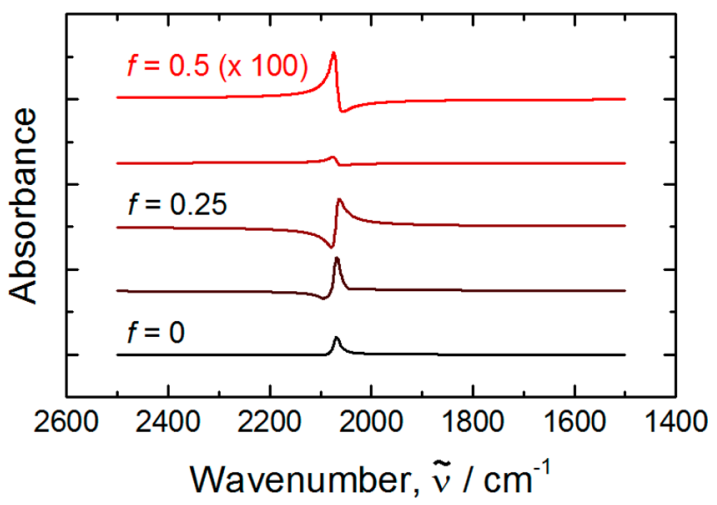

Figure 4. Simulated plots of $\varepsilon_{\mathrm{r}}, \varepsilon_{\mathrm{j}}$, and absorbance calculated using the Lorentzian model described in the text. (A) $\varepsilon_{\mathrm{r}}(\tilde{\nu})$ and $\varepsilon_{\mathrm{i}}(\tilde{\nu})$ plotted using the parameters shown. (B) Absorbance calculated using the same parameters except with values of $f$ ranging from 0 to 0.5 . Spectrum at $f=0.5$ is scaled $100 \times$.

work $\left(n_{\mathrm{H} 2 \mathrm{O}}=1.316, \tilde{\nu}_{0}=2070 \mathrm{~cm}^{-1}, B=3000\right.$ and $\gamma=15$ $\left.\mathrm{cm}^{-1}\right)$. The effect of increasing the amount of Pt in the catalyst layer is shown in Figure 4B, where it is seen that with no Pt present $(f=0)$ the band has a regular, unipolar shape. However, as the volume fraction increases to around $f=0.25$ the band becomes bipolar; the band shape continues to change at higher fractions. This behavior is very similar to that simulated by others. ${ }^{50,51,66}$ At volume fractions around 0.25 the band shape closely resembles that seen in the experimental data (Figure 2B).

3.5. Band Fitting. To test the ability of this model to fit experimental data, least-squares fitting was carried out in the region of the linear $\mathrm{CO}$ peak in Figure $2 \mathrm{~B}$. The parameters $B$, $\tilde{\nu}_{0}, f$, and $\gamma$ were allowed to vary within constraints (see Supporting Information, Table S1) until the fit converged. The fit generated from the procedure is shown in Figure 5, along with the residual difference between the fit and the data.

The fit appears to capture the shape of the peak extremely well, as demonstrated by the featureless residual. The repeatability of the fitting procedure was tested by fitting 3 similarly prepared $\mathrm{CO}$ saturated catalyst layers (see the Supporting Information, Figure S3).

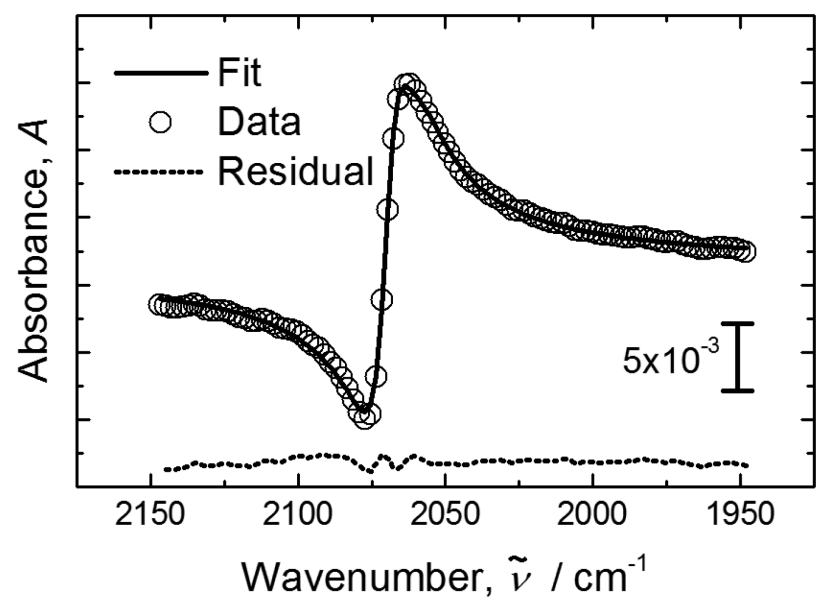

Figure 5. IR spectrum of $\mathrm{CO}$ on $\mathrm{Pt} / \mathrm{C}$ at $0.05 \mathrm{~V}$ between 1950 and $2150 \mathrm{~cm}^{-1}$ from Figure 2 (circles) fitted to the Lorentzian model described in the text (solid line). Background: spectrum at $1.2 \mathrm{~V}$ after oxidation. Fitted parameters: $f=0.25, B=521, \tilde{\nu}_{0}=2070 \mathrm{~cm}^{-1}$, and $\gamma$ $=13 \mathrm{~cm}^{-1}$.

In these cases, as well as fitting the intense band assigned to linear $\mathrm{CO}$, attempts were also made to incorporate the less intense bridging $\mathrm{CO}$ band. The mean and standard deviation calculated from the fits are shown in Table 1 . The band center

Table 1. Fitted Peak Parameters for a Saturated CO Adlayer at $0.05 \mathrm{~V}$ vs SHE According to the Fits Shown in Figure S3 for Three Similarly Prepared Films

\begin{tabular}{lcr} 
parameter & linear CO & bridging $\mathrm{CO}$ \\
$f$ & 0.25 & \\
$\tilde{\nu}_{0} / \mathrm{cm}^{-1}$ & $2069 \pm 1$ & $1825 \pm 28$ \\
$B$ & $280 \pm 230$ & $75 \pm 76$ \\
$\gamma / \mathrm{cm}^{-1}$ & $12 \pm 1$ & $99 \pm 55$ \\
\hline
\end{tabular}

and width of the linear $\mathrm{CO}$ band are found to be very reproducible between identical catalyst layers; however, the band intensity, $B$, varies dramatically between the different layers and thus cannot be compared directly between experiments. Instead, the relative intensity, $B / B_{0}$, can be defined by normalizing $B$ to the maximum value at saturation coverage. When values of $B / B_{0}$ are compared across experiments, a standard deviation of \pm 0.03 is found (see details in the Supporting Information S2). The quality of the fitting for the bridging $\mathrm{CO}$ band is markedly worse and is reflected in the deviation of the fitted band center and width. As a result, the remaining discussion focuses on the linear CO band. Note that when fitting series of spectra it is convenient to use the fitted parameters from the previous spectrum as the initial parameters for the subsequent spectrum to decrease the time taken for convergence. This approach was used here; however, frequent checks were made to ensure the initial value did not affect the result of the fit.

The fitted band parameters for the saturated $\mathrm{CO}$ adlayer measured here can be compared to values measured for adsorbed $\mathrm{CO}$ on other electrode surfaces at similar potentials (Table S2). ${ }^{10,17,29,30,35,38,40,43,44,61,62,71}$ The center of the dominant band, observed here at $2069 \pm 1 \mathrm{~cm}^{-1}$, agrees well with the values generally reported for polycrystalline $\mathrm{Pt}$ (2070$\left.2077 \mathrm{~cm}^{-1}\right)^{17,30,61,71}$ but is slightly higher than the values for linear CO adsorbed on a $60 \% \mathrm{Pt} / \mathrm{C}$ catalyst $\left(2063 \mathrm{~cm}^{-1}\right)^{71}$ and 

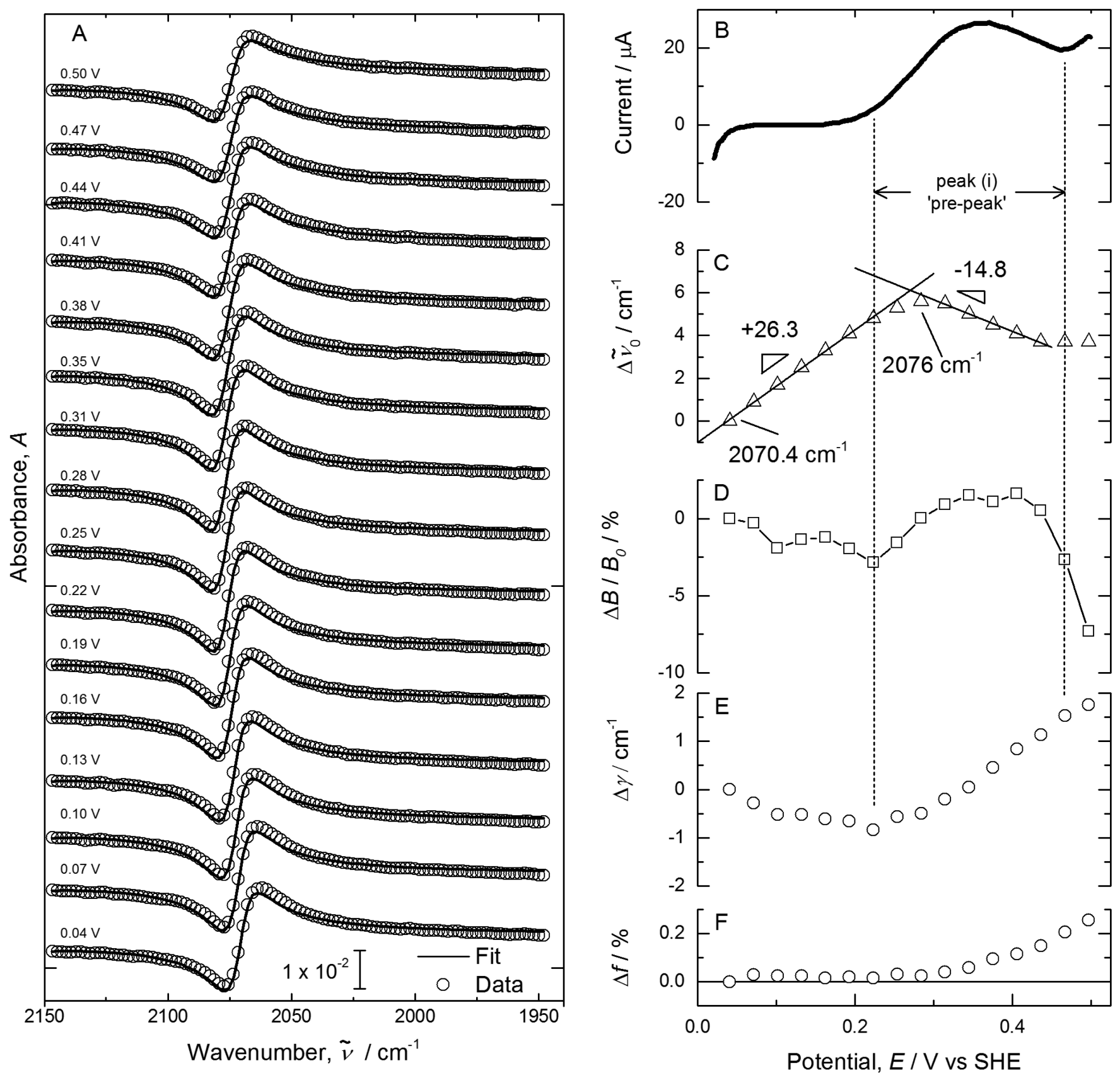

Figure 6. Fitted spectra and resulting parameters obtained during the CO oxidation peak (i) (prepeak). (A) Spectra averaged over $30 \mathrm{mV}$ windows (circles) and fits to the spectra (lines) offset for clarity. Background $1.2 \mathrm{~V}$ after oxidation. (B) Current recorded during collection of spectra. Vertical lines indicate start and end of prepeak. (C) Change in $\tilde{\nu}_{0}$ as a function of potential. Linear fits to regions of the data are shown and their gradients indicated on the figure. (D) Percentage change in relative intensity $B / B_{0}$ as a function of potential. (E) Change in bandwidth $\gamma$ as a function of potential. (F) Percentage change in $f$ as a function of potential.

for linear CO observed on $\mathrm{Pt}(111)$ single crystals. ${ }^{35,38,72}$ It is much higher than the values reported for $50 \% \mathrm{Pt} / \mathrm{C}$ in which peak fitting was used to separate out contributions from different surface sites. ${ }^{62,44}$ Significantly, the bandwidth (full width at half-maximum) is close to that measured on $\mathrm{Pt}(111)$, as opposed to the $20-40 \mathrm{~cm}^{-1}$ often reported for nanoparticle catalysts. ${ }^{27,35,40,62}$ The broad width is usually taken to indicate a broad distribution of adsorption sites and so the narrow width here could suggest that the catalyst surface is relatively uniform compared to other catalysts. Another trend apparent from the data in Table S2 is the tendency for higher wavenumbers for both large particles and higher metal loading, which may explain the relatively high wavenumber observed here.

3.6. Peak (i): Prepeak. The cyclic voltammogram in Figure $2 \mathrm{~A}$ shows three definite current peaks in the first oxidative sweep. The first peak, i, occurs at potentials much more negative than the main peaks and is therefore often known as the prepeak. ${ }^{28-30,72}$ The origin of the prepeak has been of great interest to those studying electrochemical $\mathrm{CO}$ oxidation since it represents the removal of adsorbed $\mathrm{CO}$ at an unusually low potential. Integration of the current reveals the charge passed in the region corresponds to oxidation of around $15 \%$ of the $\mathrm{CO}$ adlayer. Comparison of the first and last spectra obtained 

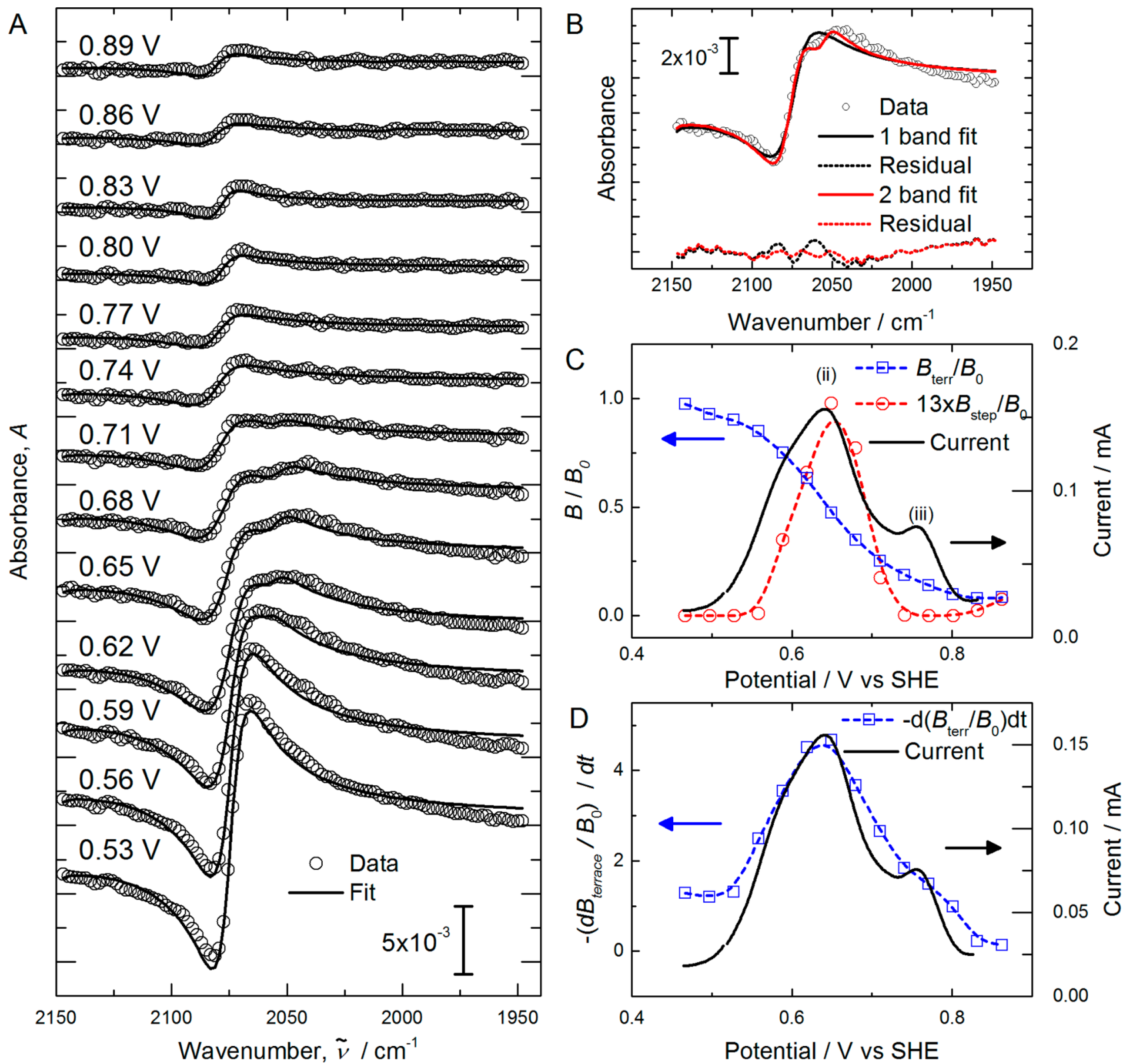

Figure 7. Analysis of CO adlayer oxidation between 0.53 and $0.89 \mathrm{~V}$ on Pt/C. (A) Spectra (circles) averaged over $30 \mathrm{mV}$ along with fits (lines) using the two oscillator model described in the text. Background: subsequent spectrum at $1.2 \mathrm{~V}$. (B) Comparison of fits to the IR spectrum of CO on Pt/C at $0.65 \mathrm{~V}$. Original one-oscillator model (black line) is compared to a two-oscillator model (red line). Data shown as circles. Residuals shown as red and black dashed lines, respectively. Background: subsequent spectrum at $1.2 \mathrm{~V}$. (C) Fitted intensities of the two linear $\mathrm{CO}$ species, assigned to terrace and step sites, observed during current peaks ii and iii along with the current itself (black line). (D) Negative time derivative of $-\mathrm{d}\left(B_{\mathrm{terr}} / B_{0}\right) /$ $\mathrm{d} t$ as a function of potential (squares), along with the current (solid line). Note dotted lines connecting points in panels $\mathrm{C}$ and $\mathrm{D}$ are for illustration only.

during the prepeak region further suggests that both linear (Figure 6A) and bridging (Figure S2) CO band intensities have decreased. The linear $\mathrm{CO}$ band around $2070 \mathrm{~cm}^{-1}$ is fitted well using the model described above as shown in Figure 6A. A more quantitative picture is revealed by comparing the current, Figure $6 \mathrm{~B}$, to the fitted parameters which are plotted as a function of potential in Figure $6 \mathrm{C}-\mathrm{F}$. In general, the changes in parameters are much smaller than their absolute value, and so the difference $\Delta$, or in the case of $B$ or $f$ the percentage difference, from the initial value at $0.0 \mathrm{~V}$ is discussed. The linear $\mathrm{CO}$ band shows a subtle change in band center, $\Delta \tilde{\nu}_{0}$, with potential, Figure $6 \mathrm{C}$. The center initially increases with potential, reaching a maximum of $2076 \mathrm{~cm}^{-1}$ at around 0.28
V. The increase is highly linear $\left(R^{2}=0.999\right)$ with a slope $\partial \Delta \tilde{\nu}_{0} /$ $\partial E=26 \mathrm{~cm}^{-1} \mathrm{~V}^{-1}$. Deviation from this linear trend is observed at the onset of prepeak current, and the sign of the slope is completely reversed by $0.3 \mathrm{~V} \partial \Delta \tilde{\nu}_{0} / \partial E=-15 \mathrm{~cm}^{-1} \mathrm{~V}^{-1}, R^{2}=$ $0.998)$. Finally, by $0.47 \mathrm{~V}$ the center stabilizes and remains constant until the end of the prepeak.

The initial positive $\partial \Delta \tilde{\nu}_{0} / \partial E$ slope is similar to the slopes reported previously for different sized $\mathrm{Pt} / \mathrm{C}$ catalysts, 22-27 $\mathrm{cm}^{-1} \mathrm{~V}^{-1}, 10,53$ and is consistent with the electrochemical Stark effect. $^{46,73}$ The subsequent negative slope is also consistent with results from $30 \mathrm{~nm}$ Pt NPs, which showed a prepeak at $0.3 \mathrm{~V}$ that correlated with a reversal in the sign of $\partial \Delta \tilde{\nu}_{0} / \partial E .^{10}$ The negative slope region has been attributed to a decrease in the 
strength of dipole coupling as the CO coverage decreases. $^{20,37,53}$ The negative slope has further been interpreted as evidence for high mobility of $\mathrm{CO}$ on the surface on the basis that diffusion would be necessary to enable the whole adlayer to equilibrate with the lower coverage and show an overall redshift. ${ }^{37}$

Beyond band center, the fitting procedure also provides values for the band intensity and width. Between 0.0 and $0.2 \mathrm{~V}$ there is a slight decrease in band intensity, $B$ (Figure 6D); however, at potentials more positive than $0.2 \mathrm{~V}$ there is a small but concerted increase. The value of this intensity increase is small, close to the observed standard deviation of $\pm 3 \%$ in measurements, yet interestingly, it correlates well with the prepeak current. A similar small increase is observed on polycrystalline $\mathrm{Pt}^{37}$ Over the same potential window, a small but steady increase in bandwidth is also observed (Figure 6E). Again, changes to linear $\mathrm{CO}$ bandwidth have been observed before in this potential window on polycrystalline $\mathrm{Pt}$, with a small shoulder on the low wavenumber side of $\mathrm{CO}$ appearing to increase with potential. ${ }^{29}$ The shoulder was taken as evidence of a transition between different adlayer structures, supposed to result from the relaxation of a highly compressed, saturated $\mathrm{CO}$ adlayer to a more stable, lower coverage. ${ }^{2,29,74}$ The increase in bandwidth observed here may similarly correspond to the growth of a small shoulder band, too small to be captured by the model as a distinct band itself (vide infra). This would then suggest that loss of $\mathrm{CO}$ during the prepeak on $\mathrm{Pt} / \mathrm{C}$ is also accompanied by a change in adlayer structure. It has previously been suggested that this structural change is prompted by the desorption of $\mathrm{CO}$ from bridge sites, providing sites for $\mathrm{OH}$ adsorption which subsequently permit oxidation of linear $\mathrm{CO} .{ }^{37}$ Due to the low intensity of the bridging $\mathrm{CO}$ in our case we are not able to confirm this on Pt/C. Finally, it is worth noting that the volume fraction, $f$, which was not fixed during the fitting, barely changes throughout the region (Figure 6F). The data were also fitted with $f$ fixed, and no significant difference was observed at these or higher potentials.

Overall, the correlation of our results with those obtained from ultrathin layers of catalyst particles on gold electrodes ${ }^{10}$ provides strong support for the fitting methodology described here, and shows that working with thick catalyst layers need not be a barrier to extracting detailed information on the catalyst surface chemistry from IR spectra.

3.7. Peaks ii and iii: Main Oxidation. Following peak i in the cyclic voltammogram there are a further two much larger current peaks (ii and iii in Figure 2A), which are accompanied by further changes to the linear $\mathrm{CO}$ band (Figure $7 \mathrm{~A}$ ). As the potential becomes more positive, the band intensity decreases; however, detailed inspection reveals the appearance and subsequent disappearance of a shoulder on the low wavenumber side of the band. To confirm that this feature is not related to the low wavenumber tailing sometimes seen in nanoparticle spectra, the spectra at 0.05 and $0.65 \mathrm{~V}$ were both processed using the Kramers-Kronig transform. Following this treatment, the shoulder is still clearly visible in the $0.65 \mathrm{~V}$ spectrum (Figure S4), demonstrating that it arises from a distinct vibrational mode. Figure $7 \mathrm{~B}$ reproduces the spectrum obtained at $0.65 \mathrm{~V}$ together with a fit to the spectrum according to the single band model described above (black line). It can be seen that the fit fails to capture the shape of the band in both the positive and negative lobes. To account for the shoulder a second Lorentzian oscillator was added into the fitting model with modified upper and lower bounds (Table S3). With the two-oscillator model (red line), the improvement in the fit can be seen immediately from the smaller values of the residuals (dashed lines).

The wavenumber of the shoulder band is still relatively high $\left(2058 \mathrm{~cm}^{-1}\right)$, suggesting it also arises from linear CO. Such a situation is possible on a nanoparticle surface since it contains many different Pt sites and thus possibilities for linear CO. To understand the sudden emergence of the shoulder band, reference can be made to stepped single-crystal model surfaces. For example, the $\mathrm{Pt}(332)$ surface comprises (111) terraces separated by (110)-type steps, making available two linear sites: terrace sites and step sites (Figure $8 \mathrm{~A}$ ). The stronger $\mathrm{Pt}-\mathrm{CO}$

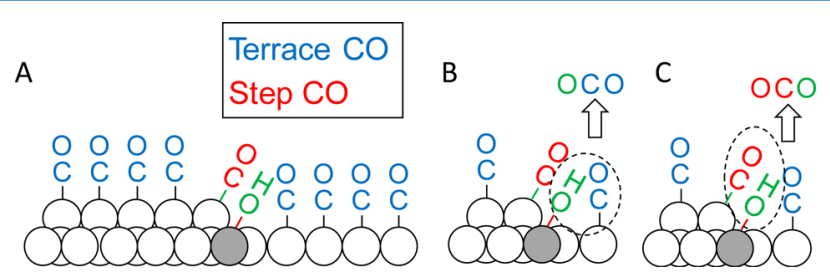

Figure 8. (A) Terrace and step CO on a model surface. (B) Oxidation of terrace $\mathrm{CO}$ at steps. (C) Oxidation of step CO. Adapted from Samjeské et al. ${ }^{37}$

interaction of $\mathrm{CO}$ adsorbed on step sites compared to terraces (due to the higher energy of the local d-band) ${ }^{24}$ leads to a decreased $\tilde{\nu}_{0}$ compared to that of $\mathrm{CO}$ on terrace sites. ${ }^{75}$ The $\mathrm{Pt}(332)$ surface has been investigated experimentally using $\mathrm{CO}$ stripping, and two linear CO stretches were detected, at 2054 and $2030 \mathrm{~cm}^{-1}$, and were assigned to terrace and step CO, respectively. ${ }^{25}$ Similar splitting of CO bands in electrochemical conditions has been observed on a wide range of surfaces, including other single crystals, ${ }^{18,76,77}$ polycrystalline $\mathrm{Pt},{ }^{37,61}$ and also NPs. ${ }^{27,45}$ The two bands observed here are therefore also tentatively assigned as terrace $\left(2074 \mathrm{~cm}^{-1}\right)$ and step (2058 $\mathrm{cm}^{-1}$ ) CO. An alternative assignment, to $\mathrm{CO}$ adsorbed on different facets, is ruled out based on the much larger redshift observed in the shoulder band $\left(18 \mathrm{~cm}^{-1}\right)$ as compared to that reported between (111) and (100) facets on Pt NPs (4 $\left.\mathrm{cm}^{-1}\right) .^{47}$

Fitting was carried out on all of the spectra obtained during the main peak region using the improved, two-oscillator model (Figure 7A). The fitted relative intensities of the higher and lower wavenumber linear $\mathrm{CO}$ bands, assigned as terrace and step $\mathrm{CO}$ respectively, $B_{\text {terr }}$ and $B_{\text {step }}$, are shown in Figure $7 \mathrm{C}$, plotted as a function of potential along with the observed (baseline corrected) current. Note that the red and blue lines are meant only as a guide, and the value of $B_{\text {step }}$ has been multiplied by 13 for ease of comparison.

At first, $B_{\text {terr }}$ and $B_{\text {step }}$ share an inverse relationship: the decrease in $B_{\text {terr }}$ is mirrored by an increase in $B_{\text {step }}$ (Figure $7 \mathrm{C}$ ). By the current maximum of peak ii, this relationship changes and both $B_{\text {terr }}$ and $B_{\text {step }}$ now decrease, the value of $B_{\text {step }}$ reaching zero around peak iii while some $B_{\text {terr }}$ remains. The change in $B_{\text {terr }}$ with potential is readily understood, particularly in terms of the current; oxidation of terrace $\mathrm{CO}$ leads to a decrease in coverage of terrace $\mathrm{CO}$ and a concomitant decrease in its intensity. The relationship between $B_{\text {step }}$ and potential is less intuitive, however, although the same anomalous increase in $B_{\text {step }}$ with potential has been observed (but not quantified) before for $\mathrm{CO}$ adsorbed on stepped single crystals ${ }^{25}$ and polycrystalline $\mathrm{Pt}^{61} \mathrm{On}$ the basis of the close proximity and wavenumber of the step and terrace $\mathrm{CO}$ vibrations, the 
anomalous behavior was rationalized using dipole coupling: when the normal modes of coupled adlayer vibrations are compared to the vibrations expected for isolated molecules, significant intensity transfer is seen to occur. ${ }^{25,37}$ Intensity transfer is always from the lower to the higher frequency vibration, ${ }^{78}$ which in this case would lead to the transfer of intensity from the step $\mathrm{CO}$ to the terrace $\mathrm{CO}$. In cases of moderate coverages of the higher wavenumber species $(\sim 10 \%)$, this transfer can leave the lower wavenumber vibration almost invisible. $^{78}$ In light of this, and previous analyses, ${ }^{25,37}$ the present observations are therefore attributed to intensity transfer. The terrace $\mathrm{CO}$ vibration acquires the majority of the band intensity, leaving the step $\mathrm{CO}$ invisible. As the coverage of terrace $\mathrm{CO}$, and $B_{\text {terr }}$, decreases, the extent of dipole-dipole coupling decreases and intensity is returned to the step $\mathrm{CO}$ vibration, resulting in its appearance in the spectrum. The subsequent decrease in $B_{\text {step }}$ is then simply the result of a decrease in step $\mathrm{CO}$ coverage as it is oxidized from these sites. This interpretation, in which $\mathrm{CO}$ on terraces is oxidized in preference to $\mathrm{CO}$ on steps (Figure $8 \mathrm{~B}$ ), contrasts with an alternative proposal based on similar qualitative data from $\mathrm{Pt} / \mathrm{C}^{61}$ There, dipole coupling was not considered, and the step $\mathrm{CO}$ intensity was taken to be proportional to step population. On this basis, a mechanism was proposed in which terrace $\mathrm{CO}$ converted to step $\mathrm{CO}$ which was then oxidized (Figure 8C). However, the prevalence of reports of coupling in these systems ${ }^{18,37,76,77}$ and the counterintuitive proposal that oxidation proceeds preferentially through $\mathrm{CO}$ adsorbed on step sites which have been demonstrated to require higher oxidation potentials on single crystal electrodes ${ }^{18}$ tend to support the former mechanism.

The relationship between terrace $\mathrm{CO}$ and the current can be understood by considering the current to be proportional to the negative time derivative of the coverage of the species being oxidized (eq 9). ${ }^{79}$ It is assumed in the first instance that the change in coverage of $\mathrm{CO}$ can be approximated by the change in intensity (eq 10) as observed previously, ${ }^{20}$ since a calibration plot of $B / B_{0}$ and $\theta_{\mathrm{CO}}$ obtained through controlled dosing of $\mathrm{CO}$ (Figure S5) is approximately linear over small changes in coverage (Figure S6). The values of $-\mathrm{d}\left(B_{\text {terr }} / B_{0}\right) / \mathrm{d} t$ are plotted with the current in Figure $7 \mathrm{D}$. It can be seen that the derivative has the same shape as the current. Such a correlation provides evidence for the current observed in peaks ii and iii being dominated by oxidation of the terrace CO.

$$
\begin{aligned}
& i \propto \frac{-\mathrm{d} \theta_{\mathrm{CO}}}{\mathrm{d} t} \\
& i \propto \frac{-\mathrm{d} B_{\text {terr }}}{\mathrm{d} t}
\end{aligned}
$$

Peak ii has been investigated previously in an electrochemical study on shape-controlled nanoparticles, where the asymmetric shape of the current peak was deconvoluted into contributions from (111) terraces at low potential and "low-coordination sites" at higher potential. ${ }^{5}$ The potential range of the two contributions reported corresponds well with the initial decrease in terrace $\mathrm{CO}$ followed by a subsequent decrease in step CO suggested by analysis of the spectra in Figure 7. This suggests that on $\mathrm{Pt} / \mathrm{C}$, step $\mathrm{CO}$ is less easily oxidized than $\mathrm{CO}$ on terraces, as on Pt model electrodes. ${ }^{18}$ In spite of the higher onset potential for removal of step $\mathrm{CO}$, its intensity reaches zero before that of terrace $\mathrm{CO}$. This has been observed on both model electrodes ${ }^{25,37,80}$ and on shape-controlled nanopar- ticles. $^{45}$ In the former case, it was suggested that step CO must migrate onto terrace sites before being oxidized, ${ }^{25}$ and this would explain the observation of step CO loss preceding terrace CO loss here. Remarkably, very similar results were also used to argue the converse: the simultaneous loss of step and terrace CO on shape-controlled NPs, where step CO removal was complete before that of terrace $\mathrm{CO}$, was attributed to the more facile oxidation of step $\mathrm{CO}$ and the migration of terrace CO onto step sites. ${ }^{45}$

Alternatively, recent reports have shown limited diffusion of CO on stepped Pt and Pt NP surfaces during oxidation, ${ }^{18,21,22}$ and thus, migration to particular sites might not occur and the faster removal of step CO may simply be a kinetic effect resulting from the smaller number of step as compared to terrace sites. Note that this low mobility regime remains compatible with previous reports of preferential adsorption at low coverage, often taken to indicate high mobility, as adsorption preference and hence mobility is seen to decrease rapidly at the moderate $\mathrm{CO}$ coverages encountered during $\mathrm{CO}$ stripping. ${ }^{48}$

Regardless of the interpretation followed here, the prior assignment of current peak ii to terrace $\mathrm{CO}$ oxidation and peak iii to step CO oxidation, ${ }^{9}$ based on the apparent inverse relationship between the magnitude of peak ii and the ratio of step to terrace sites on a series of commercial $\mathrm{Pt} / \mathrm{C}$ catalysts, is inconsistent with our deconvoluted data. Instead, more recent work has consistently found a relationship between the amount of (100) surface exposed on NP catalysts and the height of the higher potential oxidation peak iii. ${ }^{5,30,31,47,81}$ The increased potential for oxidation on (100) may be due to a difference in $\mathrm{CO}$ mobility on the two orientations, as $\mathrm{CO}$ was found to be more mobile on (111) oriented NPs than those of (100) orientation. ${ }^{82}$ Unfortunately, while there is a large redshift in linear $\mathrm{CO}$ wavenumber which enables $\mathrm{CO}$ on terraces and under-coordinated step sites to be distinguished; the same is not true among terraces of different orientation, especially on NPs (only a $4 \mathrm{~cm}^{-1}$ redshift was observed between $\mathrm{CO}$ on preferentially oriented (111) nanooctahedrons and (100) nanocubes ${ }^{83}$ ), and thus, there is no simple way to deconvolute the CO into further contributions from (111) and (100) terraces. Future experiments using, for example, the facetdependent adsorption of $\mathrm{Bi}$ and $\mathrm{Ge}$ on $\mathrm{Pt}$ to block specific sites, ${ }^{84}$ may help to resolve this.

An alternative explanation for the appearance and differing behavior of two linear $\mathrm{CO}$ bands during $\mathrm{CO}$ oxidation assigns the bands to $\mathrm{CO}$ adsorbed on two different size distributions of particle within the same catalyst layer. ${ }^{27}$ However, in these cases, not only was the particle area distribution bimodal, but the potential dependence of the bands was different from the present case in that both bands were initially present at low potential and were then lost at different rates at higher potential.

3.8. High Potential CO. In the potential region more positive than peak iii there remains a small but definite band in the linear CO region (Figure 9). This band disappears very slowly and is still just visible in the final spectrum at the end of the second potential cycle. The shape of the band is different to that observed initially, with the negative lobe much less prominent. As a result of this different shape, the high potential data were not fitted with the model presented; however, inspection reveals the band center to be around $2071 \mathrm{~cm}^{-1}$, showing negligible shift with potential (dashed line, Figure 9) and little change in width. Small particles have been shown to 


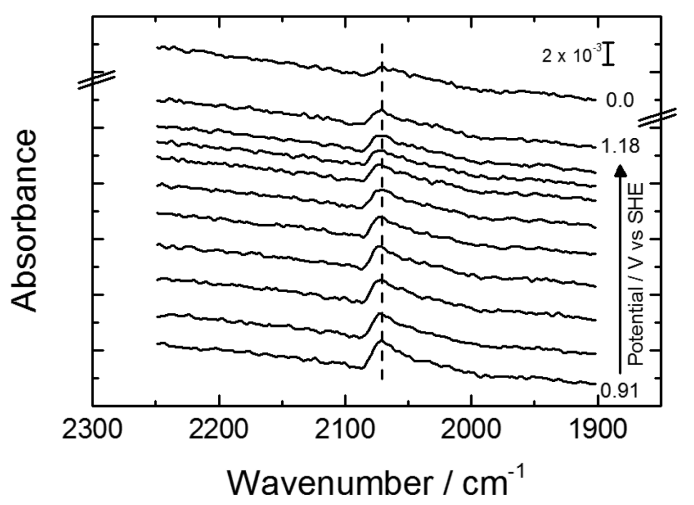

Figure 9. IR spectra of $\mathrm{CO}$ on $\mathrm{Pt} / \mathrm{C}$ recorded in the high potential region. Spectra are shown for $30 \mathrm{mV}$ intervals between 0.91 and 1.18 V. The spectrum labeled $0.0 \mathrm{~V}$ was collected at the end of the second scan. Background: $0.05 \mathrm{~V}$ before introduction of $\mathrm{CO}$.

be much less active for CO oxidation, ${ }^{10,26,40}$ with $\mathrm{CO}$ stripping peaks appearing up to $1.2 \mathrm{~V}$ vs SHE. ${ }^{40}$ In light of the band's persistence to relatively high potential, it is assigned to $\mathrm{CO}$ adsorbed on the small, isolated particles observed in the STEM (Figure 1A). This assignment also explains the absence of dipole-dipole coupling behavior seen in the other CO bands, the terraces on $1 \mathrm{~nm}$ particles not supporting extensive adlayer formation being only four to five atoms across. ${ }^{85}$

\section{CONCLUSION}

We have shown that a simple model can be used effectively to fit bipolar IR band shapes which are seen during in situ experiments on $\mathrm{Pt} / \mathrm{C}$. This model then allows detailed interpretation of the behavior of adsorbates on the Pt surface and should enable further studies on more realistic catalyst layers which tend to give rise to such effects. Step and terrace linear $\mathrm{CO}$ species are observed in our spectra and are assigned to sites on the larger agglomerated catalyst particles observed by STEM. CO stripping experiments show that CO on terraces starts to be oxidized before that on steps, consistent with previous studies on model electrodes. Furthermore, the loss of step $\mathrm{CO}$ is complete before the final current peak, ruling out assignment of this peak to oxidation from steps as suggested previously. A small contribution to the spectra from $\mathrm{CO}$ adsorbed on the smaller, isolated particles in the sample is also observed, and its very gradual loss at high potentials is consistent with sluggish oxidation kinetics previously observed for small Pt particles.

\section{ASSOCIATED CONTENT}

\section{S Supporting Information}

The Supporting Information is available free of charge on the ACS Publications website at DOI: 10.1021/acs.jpcc.7b02166.

Additional STEM images, detailed peak fits, table of reported peak positions, cyclic voltammograms and spectra used for calibration, and detailed fitted parameters (PDF)

\section{AUTHOR INFORMATION}

\section{Corresponding Author}

*E-mail: kylie.vincent@chem.ox.ac.uk. Tel: +44 (0) 1865 282611. Fax: +44 (0) 1865272690.

ORCID ${ }^{\circ}$

Philip A. Ash: 0000-0001-5264-464X
Lewys Jones: 0000-0002-6907-0731

Kylie A. Vincent: 0000-0001-6444-9382

\section{Notes}

The authors declare no competing financial interest.

\section{ACKNOWLEDGMENTS}

The staff of the Mechanical Workshop (Department of Chemistry) are thanked for assistance with cell design and fabrication. This work was carried out in the Surface Analysis Facility (Department of Chemistry) and was supported financially by the European Research Council (ERC, EnergyBioCatalysis-ERC-2010-StG-258600, I.J.M., P.A.A., and K.A.V.).

\section{REFERENCES}

(1) Beden, B.; Lamy, C.; de Tacconi, N. R.; Arvia, A. J. The Electrooxidation of CO: A Test Reaction in Electrocatalysis. Electrochim. Acta 1990, 35, 691-704.

(2) Baschuk, J. J.; Li, X. Carbon Monoxide Poisoning of Proton Exchange Membrane Fuel Cells. Int. J. Energy Res. 2001, 25, 695-713.

(3) Ehteshami, S. M. M.; Chan, S. H. A Review of Electrocatalysts with Enhanced CO Tolerance and Stability for Polymer Electrolyte Membarane Fuel Cells. Electrochim. Acta 2013, 93, 334-345.

(4) Maillard, F.; Eikerling, M.; Cherstiouk, O. V.; Schreier, S.; Savinova, E.; Stimming, U. Size Effects on Reactivity of Pt Nanoparticles in CO Monolayer Oxidation: The Role of Surface Mobility. Faraday Discuss. 2004, 125, 357-377.

(5) Urchaga, P.; Baranton, S.; Coutanceau, C.; Jerkiewicz, G. ElectroOxidation of COchem on Pt Nanosurfaces: Solution of the Peak Multiplicity Puzzle. Langmuir 2012, 28, 3658-3663.

(6) Seidel, Y. E.; Müller, M.; Jusys, Z.; Wickman, B.; Hanarp, P.; Kasemo, B.; Hörmann, U.; Kaiser, U.; Behm, R. J. Nanostructured, Glassy-Carbon-Supported Pt/GC Electrodes: The Presence of Secondary Pt Nanostructures and How to Avoid Them. J. Electrochem. Soc. 2008, 155, K171-K179.

(7) Solla-Gullón, J.; Vidal-Iglesias, F. J.; Herrero, E.; Feliu, J. M.; Aldaz, A. CO Monolayer Oxidation on Semi-Spherical and Preferentially Oriented $\left(\begin{array}{lll}1 & 0 & 0\end{array}\right)$ and $\left(\begin{array}{lll}1 & 1 & 1\end{array}\right)$ Platinum Nanoparticles. Electrochem. Commun. 2006, 8, 189-194.

(8) Zhdanov, V. P.; Kasemo, B. Simulation of CO Electrooxidation on Nm-Sized Supported Pt Particles: Stripping Voltammetry. Chem. Phys. Lett. 2003, 376, 220-225.

(9) Guerin, S.; Hayden, B. E.; Lee, C. E.; Mormiche, C.; Owen, J. R.; Russell, A. E.; Theobald, B.; Thompsett, D. Combinatorial Electrochemical Screening of Fuel Cell Electrocatalysts. J. Comb. Chem. 2004, $6,149-158$.

(10) Arenz, M.; Mayrhofer, K. J. J.; Stamenkovic, V.; Blizanac, B. B.; Tomoyuki, T.; Ross, P. N.; Markovic, N. M. The Effect of the Particle Size on the Kinetics of CO Electrooxidation on High Surface Area Pt Catalysts. J. Am. Chem. Soc. 2005, 127, 6819-6829.

(11) Gilman, S. The Mechanism of Electrochemical Oxidation of Carbon Monoxide and Methanol on Platinum. II. The "Reactant-Pair" Mechanism for Electrochemical Oxidation of Carbon Monoxide and Methanoll. J. Phys. Chem. 1964, 68, 70-80.

(12) van der Niet, M. J. T. C.; den Dunnen, A.; Juurlink, L. B. F.; Koper, M. T. M. Co-Adsorption of $\mathrm{O}$ and $\mathrm{H} 2 \mathrm{O}$ on Nanostructured Platinum Surfaces: Does OH Form at Steps? Angew. Chem., Int. Ed. 2010, 49, 6572-6575.

(13) Lebedeva, N. P.; Koper, M. T. M.; Feliu, J. M.; van Santen, R. A. Mechanism and Kinetics of the Electrochemical CO Adlayer Oxidation on $\mathrm{Pt}(111)$. J. Electroanal. Chem. 2002, 524-525, 242-251.

(14) Koper, M. T. M.; Jansen, A. P. J.; Van Santen, R. A.; Lukkien, J. J.; Hilbers, P. A. J. Monte Carlo Simulations of a Simple Model for the Electrocatalytic CO Oxidation on Platinum. J. Chem. Phys. 1998, 109, $6051-6062$

(15) McCallum, C.; Pletcher, D. An Investigation of the Mechanism of the Oxidation of Carbon Monoxide Adsorbed onto a Smooth $\mathrm{Pt}$ 
Electrode in Aqueous Acid. J. Electroanal. Chem. Interfacial Electrochem. 1976, 70, 277-290.

(16) Iwasita, T.; Nart, F. C. In Situ Infrared Spectroscopy at Electrochemical Interfaces. Prog. Surf. Sci. 1997, 55, 271-340.

(17) Yan, Y.-G.; Yang, Y.-Y.; Peng, B.; Malkhandi, S.; Bund, A.; Stimming, U.; Cai, W.-B. Study of CO Oxidation on Polycrystalline Pt Electrodes in Acidic Solution by ATR-SEIRAS. J. Phys. Chem. C 2011, 115, 16378-16388.

(18) Farias, M. J. S.; Camara, G. A.; Feliu, J. M. Understanding the CO Preoxidation and the Intrinsic Catalytic Activity of Step Sites in Stepped Pt Surfaces in Acidic Medium. J. Phys. Chem. C 2015, 119, 20272-20282.

(19) Lebedeva, N. P.; Koper, M. T. M.; Feliu, J. M.; van Santen, R. A. Role of Crystalline Defects in Electrocatalysis: Mechanism and Kinetics of CO Adlayer Oxidation on Stepped Platinum Electrodes. J. Phys. Chem. B 2002, 106, 12938-12947.

(20) Chang, S.-C.; Weaver, M. J. Coverage-Dependent Dipole Coupling for Carbon Monoxide Adsorbed at Ordered Platinum (111)Aqueous Interfaces: Structural and Electrochemical Implications. J. Chem. Phys. 1990, 92, 4582-4594.

(21) Farias, M. J. S.; Tanaka, A. A.; Tremiliosi-Filho, G.; Feliu, J. M. On the Apparent Lack of Preferential Site Occupancy and Electrooxidation of CO Adsorbed at Low Coverage onto Stepped Platinum Surfaces. Electrochem. Commun. 2011, 13, 338-341.

(22) Farias, M. J. S.; Busó-Rogero, C.; Vidal-Iglesias, F. J.; SollaGullón, J.; Camara, G. A.; Feliu, J. M. Mobility and Oxidation of Adsorbed CO on Shape-Controlled Pt Nanoparticles in Acidic Medium. Langmuir 2017, 33, 865-871.

(23) Aarons, J.; Jones, L.; Varambhia, A.; MacArthur, K. E.; Ozkaya, D.; Sarwar, M.; Skylaris, C.-K.; Nellist, P. D. Predicting the OxygenBinding Properties of Platinum Nanoparticle Ensembles by Combining High-Precision Electron Microscopy and Density Functional Theory. Nano Lett. 2017, 17, 4003-4012.

(24) Hammer, B.; Nielsen, O. H.; Nørskov, J. K. Structure Sensitivity in Adsorption: CO Interaction with Stepped and Reconstructed $\mathrm{Pt}$ Surfaces. Catal. Lett. 1997, 46, 31-35.

(25) Lebedeva, N. P.; Rodes, A.; Feliu, J. M.; Koper, M. T. M.; van Santen, R. A. Role of Crystalline Defects in Electrocatalysis: CO Adsorption and Oxidation on Stepped Platinum Electrodes As Studied by in Situ Infrared Spectroscopy. J. Phys. Chem. B 2002, 106, 98639872.

(26) Friedrich, K. A.; Henglein, F.; Stimming, U.; Unkauf, W. Size Dependence of the $\mathrm{CO}$ Monolayer Oxidation on Nanosized $\mathrm{Pt}$ Particles Supported on Gold. Electrochim. Acta 2000, 45, 3283-3293.

(27) Maillard, F.; Savinova, E. R.; Simonov, P. A.; Zaikovskii, V. I.; Stimming, U. Infrared Spectroscopic Study of CO Adsorption and Electro-Oxidation on Carbon-Supported Pt Nanoparticles: Interparticle versus Intraparticle Heterogeneity. J. Phys. Chem. B 2004, 108, 17893-17904.

(28) Marković, N. M.; Grgur, B. N.; Lucas, C. A.; Ross, P. N. Electrooxidation of $\mathrm{CO}$ and $\mathrm{H} 2 / \mathrm{CO}$ Mixtures on $\mathrm{Pt}(111)$ in Acid Solutions. J. Phys. Chem. B 1999, 103, 487-495.

(29) López-Cudero, A.; Cuesta, Á.; Gutiérrez, C. Potential Dependence of the Saturation CO Coverage of Pt Electrodes: The Origin of the Pre-Peak in CO-Stripping Voltammograms. Part 2: Pt(1 0 0). J. Electroanal. Chem. 2006, 586, 204-216.

(30) Cuesta, A.; Couto, A.; Rincón, A.; Pérez, M. C.; López-Cudero, A.; Gutiérrez, C. Potential Dependence of the Saturation CO Coverage of Pt Electrodes: The Origin of the Pre-Peak in COStripping Voltammograms. Part 3: Pt(poly). J. Electroanal. Chem. 2006, 586, 184-195.

(31) Brimaud, S.; Pronier, S.; Coutanceau, C.; Léger, J.-M. New Findings on CO Electrooxidation at Platinum Nanoparticle Surfaces. Electrochem. Commun. 2008, 10, 1703-1707.

(32) Orts, J. M.; Louis, E.; Sander, L. M.; Feliu, J. M.; Aldaz, A.; Clavilier, J. Monte Carlo Simulation of CO Adlayers Electrooxidation on $\operatorname{Pt}(111)$. Surf. Sci. 1998, 416, 371-383.

(33) Maillard, F.; Pronkin, S.; Savinova, E. R. Size Effects in Electrocatalysis of Fuel Cell Reactions on Supported Metal Nano- particles. In Fuel Cell Catalysis: A Surface Science Approach; Koper, M. T. M., Ed.; John Wiley \& Sons, Inc.: Hoboken, 2009; pp 507-566.

(34) Andreaus, B.; Maillard, F.; Kocylo, J.; Savinova, E. R.; Eikerling, M. Kinetic Modeling of COad Monolayer Oxidation on CarbonSupported Platinum Nanoparticles. J. Phys. Chem. B 2006, 110, 21028-21040.

(35) Chang, S.-C.; Roth, J. D.; Ho, Y.; Weaver, M. J. New Developments in Electrochemical Infrared Spectroscopy: Adlayer Structures of Carbon Monoxide on Monocrystalline Metal Electrodes. J. Electron Spectrosc. Relat. Phenom. 1990, 54-55, 1185-1203.

(36) Korzeniewski, C.; Severson, M. W. Applications of Infrared Spectroscopy in the Study of Catalytic Reactions and Related Adsorption Phenomena on Single Crystal Electrodes: Connections between Electrochemical and Ultra High Vacuum Surface Science. Spectrochim. Acta, Part A 1995, 51, 499-518.

(37) Samjeské, G.; Komatsu, K.; Osawa, M. Dynamics of CO Oxidation on a Polycrystalline Platinum Electrode: A Time-Resolved Infrared Study. J. Phys. Chem. C 2009, 113, 10222-10228.

(38) Villegas, I.; Weaver, M. J. Carbon Monoxide Adlayer Structures on Platinum (111) Electrodes: A Synergy between In-situ Scanning Tunneling Microscopy and Infrared Spectroscopy. J. Chem. Phys. 1994, $101,1648-1660$.

(39) Christensen, P. A.; Hamnett, A.; Munk, J.; Troughton, G. L. An in Situ FTIR Study of the Electrochemical Oxidation of Methanol at Small Platinum Particles. J. Electroanal. Chem. 1994, 370, 251-258.

(40) Friedrich, K. A.; Henglein, F.; Stimming, U.; Unkauf, W. Investigation of Pt Particles on Gold Substrates by IR Spectroscopy Particle Structure and Catalytic Activity. Colloids Surf., A 1998, 134, 193-206.

(41) Zhu, Y.; Uchida, H.; Watanabe, M. Oxidation of Carbon Monoxide at a Platinum Film Electrode Studied by Fourier Transform Infrared Spectroscopy with Attenuated Total Reflection Technique. Langmuir 1999, 15, 8757-8764.

(42) Rice, C.; Tong; Oldfield, E.; Wieckowski, A.; Hahn, F.; Gloaguen, F.; Léger, J.-M.; Lamy, C. In Situ Infrared Study of Carbon Monoxide Adsorbed onto Commercial Fuel-Cell-Grade CarbonSupported Platinum Nanoparticles: Correlation with ${ }^{13}$ C NMR Results. J. Phys. Chem. B 2000, 104, 5803-5807.

(43) Park, S.; Tong, Y.; Wieckowski, A.; Weaver, M. J. Infrared Reflection-Absorption Properties of Platinum Nanoparticle Films on Metal Electrode Substrates: Control of Anomalous Optical Effects. Electrochem. Commun. 2001, 3, 509-513.

(44) Kunimatsu, K.; Sato, T.; Uchida, H.; Watanabe, M. Adsorption/ Oxidation of $\mathrm{CO}$ on Highly Dispersed Pt Catalyst Studied by Combined Electrochemical and ATR-FTIRAS Methods: Oxidation of CO Adsorbed on Carbon-Supported Pt Catalyst and Unsupported Pt Black. Langmuir 2008, 24, 3590-3601.

(45) Nakamura, M.; Hanioka, Y.; Ouchida, W.; Yamada, M.; Hoshi, N. Estimation of Surface Structure and Carbon Monoxide Oxidation Site of Shape-Controlled Pt Nanoparticles. ChemPhysChem 2009, 10, 2719-2724

(46) Rodes, A.; Pérez, J. M.; Aldaz, A. Vibrational Spectroscopy. In Handbook of Fuel Cells; Vielstich, W., Lamm, A., Gasteiger, H. A., Yokokawa, H., Eds.; John Wiley \& Sons, Ltd: Chichester, 2010.

(47) Brimaud, S.; Jusys, Z.; Behm, R. J. Shape-Selected Nanocrystals for in Situ Spectro-Electrochemistry Studies on Structurally Well Defined Surfaces under Controlled Electrolyte Transport: A Combined in Situ ATR-FTIR/Online DEMS Investigation of CO Electrooxidation on Pt. Beilstein J. Nanotechnol. 2014, 5, 735-746.

(48) Liu, H.-X.; Tian, N.; Ye, J.-Y.; Lu, B.-A.; Ren, J.; Huangfu, Z.-C.; Zhou, Z.-Y.; Sun, S.-G. A Comparative Study of CO Adsorption on Tetrahexahedral Pt Nanocrystals and Interrelated Pt Single Crystal Electrodes by Using Cyclic Voltammetry and in Situ FTIR Spectroscopy. Faraday Discuss. 2015, 176, 409-428.

(49) Lu, G.-Q.; Sun, S.-G.; Chen, S.-P.; Cai, L.-R. Novel Properties of Dispersed $\mathrm{Pt}$ and $\mathrm{Pd}$ Thin Layers Supported on GC for CO Adsorption Studied Using in Situ MS-FTIR Reflection Spectroscopy. J. Electroanal. Chem. 1997, 421, 19-23. 
(50) Pecharromán, C.; Cuesta, A.; Gutiérrez, C. Comments on the Paper by M.-S. Zheng and S.-G. Sun Entitled "In Situ FTIR Spectroscopic Studies of CO Adsorption on Electrodes with Nanometer-Scale Thin Films of Ruthenium in Sulfuric Acid Solutions" [J. Electroanal. Chem. 500 (2001) 223]. J. Electroanal. Chem. 2002, 529, $145-154$.

(51) Pecharromán, C.; Cuesta, A.; Gutiérrez, C. Calculation of Adsorption-Induced Differential External Reflectance Infrared Spectra of Particulate Metals Deposited on a Substrate. J. Electroanal. Chem. 2004, 563, 91-109.

(52) Friedrich, K. A.; Henglein, F.; Stimming, U.; Unkauf, W. In-Situ Vibrational Spectroscopy on Pt Electrocatalysts. Electrochim. Acta 2001, 47, 689-694.

(53) Stamenković, V.; Arenz, M.; Ross, P. N.; Marković, N. M. Temperature-Induced Deposition Method for Anchoring Metallic Nanoparticles onto Reflective Substrates for in Situ Electrochemical Infrared Spectroscopy. J. Phys. Chem. B 2004, 108, 17915-17920.

(54) Zhang, H.; Wang, X.; Zhang, J.; Zhang, J. Conventional Catalyst Ink, Catalyst Layer and MEA Preparation. In PEM Fuel Cell Electrocatalysts and Catalyst Layers; Zhang, J., Ed.; Springer: London, 2008; pp 889-916.

(55) McPherson, I. J.; Ash, P. A.; Jacobs, R. M. J.; Vincent, K. A. Formate Adsorption on Pt Nanoparticles during Formic Acid ElectroOxidation: Insights from in Situ Infrared Spectroscopy. Chem. Commun. 2016, 52, 12665-12668.

(56) Smith, T. J.; Stevenson, K. J. 4 - Reference Electrodes. In Handbook of Electrochemistry; Zoski, C. G., Ed.; Elsevier: Amsterdam, 2007; pp 73-110.

(57) Nesselberger, M.; Ashton, S. J.; Wiberg, G. K. H.; Arenz, M. Design, Development, and Demonstration of a Fully LabVIEW Controlled in Situ Electrochemical Fourier Transform Infrared Setup Combined with a Wall-Jet Electrode to Investigate the Electrochemical Interface of Nanoparticulate Electrocatalysts under Reaction Conditions. Rev. Sci. Instrum. 2013, 84, 074103.

(58) Nellist, P. D.; Pennycook, S. J. Direct Imaging of the Atomic Configuration of Ultradispersed Catalysts. Science 1996, 274, 413415.

(59) Schmidt, T. J.; Gasteiger, H. A. Rotating Thin-Film Method for Supported Catalysts. In Handbook of Fuel Cells; John Wiley \& Sons, Ltd., 2010.

(60) Marković, N. M.; Ross, P. N., Jr. Surface Science Studies of Model Fuel Cell Electrocatalysts. Surf. Sci. Rep. 2002, 45, 117-229.

(61) Kunimatsu, K.; Sato, T.; Uchida, H.; Watanabe, M. Role of Terrace/Step Edge Sites in CO Adsorption/Oxidation on a Polycrystalline Pt Electrode Studied by in Situ ATR-FTIR Method. Electrochim. Acta 2008, 53, 6104-6110.

(62) Sato, T.; Kunimatsu, K.; Uchida, H.; Watanabe, M. Adsorption/ Oxidation of $\mathrm{CO}$ on Highly Dispersed Pt Catalyst Studied by Combined Electrochemical and ATR-FTIRAS Methods: Part 1. ATRFTIRAS Spectra of CO Adsorbed on Highly Dispersed Pt Catalyst on Carbon Black and Carbon Un-Supported Pt Black. Electrochim. Acta 2007, 53, 1265-1278.

(63) Bjerke, A. E.; Griffiths, P. R.; Theiss, W. Surface-Enhanced Infrared Absorption of CO on Platinized Platinum. Anal. Chem. 1999, 71, 1967-1974.

(64) Osawa, M.; Ataka, K. Electromagnetic Mechanism of Enhanced Infrared Absorption of Molecules Adsorbed on Metal Island Films. Surf. Sci. 1992, 262, L118-L122.

(65) Osawa, M.; Ataka, K.; Yoshii, K.; Yotsuyanagi, T. SurfaceEnhanced Infrared ATR Spectroscopy for in Situ Studies of Electrode/ Electrolyte Interfaces. J. Electron Spectrosc. Relat. Phenom. 1993, 64-65, 371-379.

(66) Su, Z.-F.; Sun, S.-G.; Wu, C.-X.; Cai, Z.-P. Study of Anomalous Infrared Properties of Nanomaterials through Effective Medium Theory. J. Chem. Phys. 2008, 129, 044707.

(67) Rakić, A. D.; Djurišíc, A. B.; Elazar, J. M.; Majewski, M. L. Optical Properties of Metallic Films for Vertical-Cavity Optoelectronic Devices. Appl. Opt. 1998, 37, 5271-5283.
(68) Peterson, C. W.; Knight, B. W. Causality Calculations in the Time Domain: An Efficient Alternative to the Kramers-Kronig Method. J. Opt. Soc. Am. 1973, 63, 1238.

(69) Ohta, K.; Ishida, H. Comparison among Several Numerical Integration Methods for Kramers-Kronig Transformation. Appl. Spectrosc. 1988, 42, 952-957.

(70) Green, M. A.; Keevers, M. J. Optical Properties of Intrinsic Silicon at $300 \mathrm{~K}$. Prog. Photovoltaics 1995, 3, 189-192.

(71) Park, S.; Wasileski, S. A.; Weaver, M. J. Electrochemical Infrared Characterization of Carbon-Supported Platinum Nanoparticles: A Benchmark Structural Comparison with Single-Crystal Electrodes and High-Nuclearity Carbonyl Clusters. J. Phys. Chem. B 2001, 105, 97199725.

(72) López-Cudero, A.; Cuesta, A.; Gutiérrez, C. Potential Dependence of the Saturation CO Coverage of Pt Electrodes: The Origin of the Pre-Peak in CO-Stripping Voltammograms. Part 1: Pt(1 1 1). J. Electroanal. Chem. 2005, 579, 1-12.

(73) Wasileski, S. A.; Koper, M. T. M.; Weaver, M. J. FieldDependent Chemisorption of Carbon Monoxide on Platinum-Group (111) Surfaces: Relationships between Binding Energetics, Geometries, and Vibrational Properties as Assessed by Density Functional Theory. J. Phys. Chem. B 2001, 105, 3518-3530.

(74) Leiva, E. P. M.; Santos, E.; Iwasita, T. The Effect of Adsorbed Carbon Monoxide on Hydrogen Adsorption and Hydrogen Evolution on Platinum. J. Electroanal. Chem. Interfacial Electrochem. 1986, 215, 357-367.

(75) Brandt, R. K.; Sorbello, R. S.; Greenler, R. G. Site-Specific, Coupled-Harmonic-Oscillator Model of Carbon Monoxide Adsorbed on Extended, Single-Crystal Surfaces and on Small Crystals of Platinum. Surf. Sci. 1992, 271, 605-615.

(76) Kim, C. S.; Tornquist, W. J.; Korzeniewski, C. Infrared Spectroscopy as a Probe of Carbon Monoxide Adsorption at platinum(335) under Aqueous Electrochemical Conditions. J. Phys. Chem. 1993, 97, 6484-6491.

(77) Kim, C. S.; Korzeniewski, C. Vibrational Coupling as a Probe of Adsorption at Different Structural Sites on a Stepped Single-Crystal Electrode. Anal. Chem. 1997, 69, 2349-2353.

(78) Hollins, P. The Influence of Surface Defects on the Infrared Spectra of Adsorbed Species. Surf. Sci. Rep. 1992, 16, 51-94.

(79) Srinivasan, S.; Gileadi, E. The Potential-Sweep Method: A Theoretical Analysis. Electrochim. Acta 1966, 11, 321-335.

(80) Koper, M. T. M.; Lebedeva, N. P.; Hermse, C. G. M. Dynamics of $\mathrm{CO}$ at the Solid/Liquid Interface Studied by Modeling and Simulation of $\mathrm{CO}$ Electro-Oxidation on $\mathrm{Pt}$ and $\mathrm{PtRu}$ Electrodes. Faraday Discuss. 2002, 121, 301-311.

(81) Kinge, S.; Urgeghe, C.; De Battisti, A.; Bönnemann, H. Dependence of CO Oxidation on Pt Nanoparticle Shape: A ShapeSelective Approach to the Synthesis of PEMFC Catalysts. Appl. Organomet. Chem. 2008, 22, 49-54.

(82) Coutanceau, C.; Urchaga, P.; Baranton, S. Diffusion of Adsorbed CO on Platinum (100) and (111) Oriented Nanosurfaces. Electrochem. Commun. 2012, 22, 109-112.

(83) Brimaud, S.; Solla-Gullón, J.; Weber, I.; Feliu, J. M.; Behm, R. J. Formic Acid Electrooxidation on Noble-Metal Electrodes: Role and Mechanistic Implications of $\mathrm{pH}$, Surface Structure, and Anion Adsorption. ChemElectroChem 2014, 1, 1075-1083.

(84) Solla-Gullón, J.; Vidal-Iglesias, F. J.; Rodríguez, P.; Herrero, E.; Feliu, J. M.; Clavilier, J.; Aldaz, A. In Situ Surface Characterization of Preferentially Oriented Platinum Nanoparticles by Using Electrochemical Structure Sensitive Adsorption Reactions. J. Phys. Chem. B 2004, 108, 13573-13575.

(85) Dobrin, S. CO Oxidation on Pt Nanoclusters, Size and Coverage Effects: A Density Functional Theory Study. Phys. Chem. Chem. Phys. 2012, 14, 12122-12129. 